\title{
Sistema de blocos prensados e doses de adubo de liberação lenta na formação de porta-enxerto cítrico
}

\author{
Pressed blocks system and slow release fertilizer levels for citrus rootstock formation
}

\author{
Luiz Augusto Lopes Serrano ${ }^{1}$ Cláudia Sales Marinho ${ }^{2}$ Deborah Guerra Barroso ${ }^{2}$ \\ Almy Júnior Cordeiro de Carvalho
}

\section{RESUMO}

Devido à restrição que os tubetes impõem ao crescimento lateral do sistema radicular, o uso de materiais orgânicos prensados está sendo utilizado para a produção de mudas de espécies florestais. O objetivo do trabalho foi avaliar a produção do porta-enxerto cítrico limoeiro 'Cravo' no sistema de blocos prensados até a repicagem, e o efeito deste sistema e de doses de um fertilizante de liberação lenta sobre o crescimento desse porta-enxerto até o ponto de enxertia. Avaliaram-se três sistemas de produção até a repicagem: em tubetes preenchidos com substrato comercial composto por casca de pínus; em tubetes preenchidos com substrato composto pela mistura entre bagaço de cana e torta de filtro (3:2; v:v); e em "blocos prensados" constituídos pela prensagem do substrato composto pela mistura entre bagaço de cana e torta de filtro (3:2; v:v). Da repicagem à enxertia, foram empregadas cinco doses de Osmocote $^{\circledR}$ (NPK 14-14-14): 5, 10, 15, 20 e 25g planta ${ }^{-1}$. As mudas provenientes do sistema de blocos prensados atingiram o ponto de repicagem e o de enxertia mais rapidamente que as produzidas em tubetes. No ponto de enxertia, estas apresentaram maiores médias de diâmetro de caule e massa seca da parte aérea e do sistema radicular. O sistema utilizado na produção do porta-enxerto também interferiu na resposta das mudas à adubação empregada.

Palavras-chave: Citrus limonia, recipiente, propagação, substratos, adubação.

\section{ABSTRACT}

Due to the restriction that the stiff plastic tubes impose to the lateral growth of the root system, the use of pressed organic materials has been proposed for the production of forests species seedlings. The research was carried out with the objectives of evaluating the production of rootstock 'Rangpur' lime tree in pressed blocks until the transplant, and the effect of those systems were evaluated and doses of slow release fertilizer on the growth of that rootstock until the grafting point. Three production systems were evaluated: in stiff plastic tubes filled up with commercial substrate composed by pinus bark; in stiff plastic tubes filled up with substrate composed by sugarcane bagasse and industrial sugarcane plant residues, $(3: 2 ; v: v)$; and production in "pressed blocks" constituted by the press of the substrate used in the system 2. From transplant at the grafting point, five doses of Osmocote ${ }^{\circledR}$ (NPK 14-14-14) were used: 5, 10, 15, 20 e $25 \mathrm{~g} \mathrm{plant}^{-1}$. Compared to the seedlings grown in tubes, seedlings coming of the system of pressed blocks reached the transplant and the grafting point more quickly. In the grafting point they resulted in rootstocks with larger stem diameter, larger root and aerial part dry matter. The system used in the production of the rootstock also interfered in the answer of the plants to the employed manuring.

Key words: Citrus limonia, container, propagation, substrates, fertilization.

\section{INTRODUÇÃO}

Em ambientes protegidos, os porta-enxertos cítricos são semeados, geralmente, em tubetes de plásticos rígidos de onde são transplantados (repicagem), após seleção das mudas, para sacos plásticos ou citrovasos (CARVALHO, 2001). Apesar da praticidade que a produção de mudas em tubetes oferece, a pequena dimensão destes recipientes causa alguns inconvenientes como a disponibilização de um pequeno volume de substrato e a exigência de aplicações de doses elevadas de nutrientes, devido às perdas por lixiviação, resultantes da necessidade de regas freqüentes (BARROSO et al., 2000).

${ }^{1}$ Instituto Capixaba de Pesquisa (INCAPER), Centro Regional de Desenvolvimento Rural Nordeste (CRDR), Rodovia BR 101 norte, Km 151, CP 62, 29900-970, Linhares, ES, Brasil. E-mail: lalserrano@incaper.es.gov.br. Autor para correspondência. ${ }^{2}$ Universidade Federal do Norte Fluminense (UENF), Centro de Ciências e Teconologias Agropecuárias (CCTA), Laboratório de Fitotecnia, Av. Alberto Lamego, 2000, Horto, 28013-600, Campos dos Goytacazes, RJ, Brasil. 
O uso de recipientes com pequenas dimensões tem, também, efeito inibitório sobre o crescimento lateral do sistema radicular, impondo uma restrição similar àquela resultante da compactação do solo, limitando o crescimento e o desenvolvimento de várias espécies pela redução da área foliar, altura e produção de biomassa (MARSCHNER, 1995). A poda aérea que ocorre no fundo dos tubetes (necrose da coifa e meristema apical das raízes quando em contato com o ar atmosférico) promove, também, significativa modificação na arquitetura original do sistema radicular, achatando-o, principalmente devido à paralisação do crescimento da raiz pivotante. Essas deformações tendem a continuar após a fase de viveiro, ocasionando maiores perdas de mudas no campo (REIS et al., 1989; BARROSO et al., 2000).

O uso de material orgânico prensado compondo um recipiente natural para mudas é um sistema difundido com sucesso entre os países escandinavos, notadamente na Finlândia, e vem sendo testado, com êxito, no Brasil para a produção de mudas de espécies florestais como Eucalyptus spp. (BARROSO et al., 2000; LELES et al., 2000; MORGADO et al., 2000) e Pinus spp. (NOVAES, 1998). Neste sistema, as mudas são produzidas em blocos de substratos prensados e apresentam uma morfologia radicular mais próxima à natural, com desenvolvimento do sistema radicular sem deformações já que a ausência de paredes evita o confinamento ou direcionamento das raízes. Este sistema também proporciona a exploração de um volume de substrato cinco vezes maior que o dos tubetes, sem gastar mais espaço no viveiro (BARROSO et al., 2000) e exige menor número de irrigações (LELES et al., 2000).

A produção de mudas cítricas em recipientes demanda uma exigência de aplicações periódicas de nutrientes, em função da lixiviação e do volume de substrato limitado (CARVALHO, 2001). Uma das alternativas para aumentar a eficiência dessas adubações seria a realização de maior parcelamento, principalmente quando se trata do nitrogênio. Tal prática, entretanto, apresenta aumento significativo no custo operacional, mesmo se considerar o uso da fertirrigação, visto que os espaços entre os tubetes representam cerca de 78\% das bandejas (BARROSO et al., 2000). Outra alternativa seria a utilização de fontes que apresentam uma liberação mais lenta ou controlada dos nutrientes, que pode reduzir gastos com mão-deobra, energia e, também, manter um sincronismo de liberação dos nutrientes com as necessidades de crescimento e desenvolvimento das plantas (ZEKRI \& KOO, 1992).
Os nutrientes encapsulados por resinas especiais são liberados através de sua estrutura porosa e estes atingem o sistema radicular das plantas mais lentamente. Ao absorver os nutrientes, as raízes causam uma depleção na concentração dos nutrientes nas proximidades da zona radicular induzindo um sistema de liberação de nutrientes por osmose. A taxa de liberação dos nutrientes encapsulados é mais alta em temperaturas mais elevadas coincidindo com o período de crescimento mais ativo das plantas (SHAVIT et al., 1997; TOMASZEWSKA et al., 2002).

O sistema de produção do porta-enxerto, utilizado antes da repicagem pode, como hipótese, causar alterações no sistema radicular das mudas e, assim, modificar a resposta destas à adubação. Assim, o objetivo deste trabalho foi avaliar a produção do porta-enxerto cítrico limoeiro 'Cravo' no sistema de blocos prensados até a fase de repicagem, e verificar o efeito deste sistema e de doses de um fertilizante de liberação lenta, sobre o crescimento das mudas após a repicagem.

\section{MATERIAL E MÉTODOS}

O experimento foi conduzido em viveiro telado localizado na Universidade Estadual do Norte Fluminense 'Darcy Ribeiro', em Campos dos Goytacazes, RJ, entre julho de 2001 e março de 2002. A temperatura média do período foi de $23,3^{\circ} \mathrm{C}$.

Na primeira etapa do experimento, da semeadura até a repicagem, as mudas foram conduzidas em três sistemas de produção: Sistema 1: em tubetes $\left(50 \mathrm{~cm}^{3}\right)$ preenchidos com substrato comercial composto por casca de pínus moída e vermiculita; Sistema 2: em tubetes $\left(50 \mathrm{~cm}^{3}\right)$ preenchidos com substrato composto pela mistura entre bagaço de cana-de-açúcar moído e torta de filtro (3:2;v:v); e Sistema 3: em blocos prensados confeccionados pela prensagem do substrato utilizado no sistema 2 .

Os resultados das análises químicas do substrato comercial e do substrato composto pela mistura entre bagaço de cana-de-açúcar moído e torta de filtro foram: $\mathrm{pH}$ em água 5,2 e 6,5; 10,6 e 18,2 $\mathrm{g} \mathrm{kg}^{-1} \mathrm{de}$ $\mathrm{N} ; 13,8$ e 27,9g kg-1 de P; 4,9 e 2,4g kg-1 de K; 23,4 e 48,0g kg-1 de Ca; 20,4 e 4,9g kg-1 de Mg; 3,5 e 6,7g kg-1 de S; 463 e $288 \mathrm{~g} \mathrm{~kg}^{-1}$ de C; 5.640 e $15.600 \mathrm{mg} \mathrm{kg}^{-1}$ de Fe; 24 e $88 \mathrm{mg} \mathrm{kg}^{-1}$ de $\mathrm{Cu}$; 40 e $206 \mathrm{mg} \mathrm{kg}^{-1}$ de Zn; 205 e $860 \mathrm{mg} \mathrm{kg}^{-1}$ de Mn; e condutividade elétrica de 5,27 e $4,01 \mathrm{dS} \mathrm{m}{ }^{-1}$, respectivamente. Quanto às análises físicas dos substratos utilizados, os resultados foram 85, 92 e $91 \%$ de porosidade total, sendo 45,78 e $51 \%$ correspondente à macroporosidade e 40, 15 e $40 \%$ correspondente à microporosidade; e densidade 
aparente de 466, 190 e $211 \mathrm{~g} \mathrm{~L}^{-1}$ respectivamente para os substratos utilizados nos sistemas 1,2 e 3 .

No preparo dos dois substratos utilizados na primeira fase, houve a adição de $300 \mathrm{~g} \mathrm{~m}^{-3}$ do adubo de liberação lenta Osmocote ${ }^{\circledR}$ (NPK 14-14-14), que foi misturado aos substratos.

Os blocos prensados foram confeccionados seguindo seis etapas seqüenciais: trituração dos resíduos decompostos, uniformização do comprimento das fibras, tratamento com brometo de metila, mistura dos materiais em betoneira, prensagem (prensa hidráulica a $10 \mathrm{~kg} \mathrm{~cm}^{-2}$, por 15 minutos) e secagem dos blocos prensados (MORGADO et al., 2000). No final do processo, os blocos possuíam $60 \mathrm{~cm}$ de comprimento, $40 \mathrm{~cm}$ de largura, $10 \mathrm{~cm}$ de altura e com 96 pontos de semeadura, em espaçamento de $5 \mathrm{~cm}$. Os blocos foram colocados em caixas de madeira com fundos telados (malha de $1 \mathrm{~cm}$ ).

Em cada ponto de semeadura, foram colocadas três sementes que tiveram o tegumento externo (testa) retirado, objetivando-se, assim, aumentar a taxa de germinação e o índice de velocidade de germinação (SERRANO et al., 2003).

A primeira etapa do experimento foi conduzida sob delineamento inteiramente casualizado, utilizando-se 35 repetições, sendo cada repetição constituída por uma muda.

Quando as mudas dos três sistemas atingiram a altura média de $10 \mathrm{~cm}$, medidos a partir do colo, estas foram submetidas à repicagem. Nesse momento, foram avaliados a altura, o diâmetro do caule (a $1 \mathrm{~cm}$ do colo) e o número de folhas.

Para a segunda etapa do experimento, da repicagem até o ponto de enxertia, foram selecionadas 35 mudas homogêneas quanto à altura e ao número de folhas de cada sistema de produção utilizado na primeira fase. Estas mudas foram transplantadas para citrovasos $\left(3,8 \mathrm{dm}^{3}\right)$ preenchidos pelo mesmo substrato em que vinham sendo cultivadas. Na segunda etapa, os substratos utilizados nos citrovasos não foram prensados.

Para a repicagem, as mudas provenientes do sistema de blocos prensados foram individualizadas em torrões por meio de cortes longitudinal e transversal feitos com lâmina de serra.

Aos substratos foram adicionadas cinco doses de Osmocote ${ }^{\circledR}$ (NPK 14-14-14): 5; 10; 15; 20 e 25 planta $^{-1}\left(1,32 ; 2,64 ; 3,96 ; 5,28\right.$ e $6,60 \mathrm{~kg} \mathrm{~m}^{-3}$ de substrato). Também foram adicionados aos substratos $2,0 \mathrm{~kg} \mathrm{~m}^{-3}$ de superfosfato simples, para suprir a adubação fosfatada requerida pelas mudas cítricas (REZENDE et al., 1995). Os adubos foram adicionados e misturados aos substratos, antes do preenchimento dos citrovasos, até homogeneização.
A partir da repicagem, as mudas foram pulverizadas mensalmente com uma solução composta por: $1 \mathrm{~g} \mathrm{~L}^{-1}$ de oxicloreto de cobre; $1 \mathrm{~g} \mathrm{~L}^{-1}$ de ácido bórico; $4 \mathrm{~g} \mathrm{~L}^{-1}$ de sulfato de magnésio; 3,5g $\mathrm{L}^{-1}$ de sulfato de zinco; $2,5 \mathrm{~g} \mathrm{~L}^{-1}$ de sulfato de manganês e $5 \mathrm{~g} \mathrm{~L}^{-1}$ de uréia. Na primeira pulverização, houve também a adição de $0,2 \mathrm{~g} \mathrm{~L}^{-1}$ de molibdato de sódio.

A segunda etapa do experimento foi conduzida sob delineamento inteiramente casualizado, em esquema fatorial 3x5, utilizando-se sete repetições, com cada repetição constituída por uma muda.

O crescimento das mudas foi acompanhado quinzenalmente através de medições do diâmetro do caule (aos $10 \mathrm{~cm}$ do colo), sendo este a característica morfológica que determina a possibilidade de execução da enxertia (REZENDE et al., 1995). Quando as mudas dos três sistemas atingiram o diâmetro de caule médio de $8 \mathrm{~mm}$, estas foram consideradas no ponto de enxertia (CARVALHO, 2001). Neste momento, foram avaliados a altura das mudas, o diâmetro do caule, o número de folhas, a área foliar, a massa seca da parte aérea e a massa seca do sistema radicular.

A altura das mudas foi medida com régua milimetrada e o diâmetro do caule foi medido com paquímetro digital. A área foliar foi mensurada utilizando-se o aparelho LI-3100 area meter ${ }^{\circledR}$. As folhas, os caules e as raízes foram colocados para secar em estufa ( $70^{\circ} \mathrm{C}$ por 72 horas) para posterior determinação, por gravimetria, da massa seca do sistema radicular e da parte aérea.

Os valores obtidos para as características avaliadas foram submetidos a análises de variância. As médias dos sistemas de produção foram comparadas pelo teste Tukey e as doses de adubo de liberação lenta foram submetidas a análise de regressão, ambos a 5\% de probabilidade de erro.

\section{RESULTADOS E DISCUSSÃO}

As mudas provenientes do sistema de blocos prensados apresentaram-se mais precoces do que as demais, pois atingiram o ponto de repicagem aos 63 dias após a semeadura (DAS), enquanto a média geral foi aos 73 DAS (dados não mostrados). Essas médias são consideradas satisfatórias, pois CARVALHO (2001) cita um período entre 90 e 120 DAS para obtenção de mudas cítricas aptas à repicagem.

No ponto de repicagem, as mudas do sistema de blocos prensados apresentaram as maiores médias para altura e número de folhas (Tabela 1). O maior volume do substrato permitiu maior desenvolvimento das raízes do porta-enxerto, possibilitando maior exploração e absorção de 
Tabela 1 - Médias da altura, diâmetro do caule e número de folhas das mudas de limoeiro ‘Cravo’ no momento da repicagem (73 dias após semeadura) em três sistemas de produção.

\begin{tabular}{llll}
\hline Sistemas de produção & Altura $(\mathrm{cm})$ & Diâmetro (mm) & N. ${ }^{\circ}$ folhas \\
\hline 1- Casca de pinus (tubetes) & $10,19 \mathrm{~b}$ & 2,03 & $8,77 \mathrm{~b}$ \\
2- BC + TF (tubetes) & $10,78 \mathrm{~b}$ & 1,99 & $8,57 \mathrm{~b}$ \\
3- BC + TF (blocos prensados) & $12,04 \mathrm{a}$ & 2,02 & $9,43 \mathrm{a}$ \\
& & & 8,92 \\
Média Geral & 11,00 & 2,01 & 0,54 \\
D.M.S. & 0,86 & n.s. & 10,72 \\
CV (\%) & 13,77 & 9,78 & \\
\hline
\end{tabular}

Médias na coluna, seguidas por letras diferentes, são diferentes em nível de 5\% de probabilidade de erro pelo teste de Tukey. ${ }^{(1)}$ BC: bagaço de cana; TF: torta de filtro.

nutrientes, favorecendo, assim, maior crescimento da parte aérea.

Comparando-se com a produção em tubetes, o sistema de blocos prensados mostrou-se mais vantajoso até a fase de repicagem em relação à precocidade das mudas. A utilização do sistema de blocos prensados também conferiu às mudas de quatro espécies de Eucalyptus spp. (BARROSO et al., 2000; MORGADO et al., 2000, LELES et al., 2000) e de duas de Pinus spp. (CARNEIRO et al.; 1988; NOVAES, 1998) maiores valores de altura e de diâmetro do colo quando comparadas às produzidas em tubetes, apresentando maior precocidade para o plantio no campo.

As mudas provindas do sistema de blocos prensados (Sistema 3), também apresentaram maior precocidade para atingirem o ponto de enxertia, pois a média do diâmetro do caule de 8,0 mm foi atingida aos 137 dias após a repicagem (210 DAS). O ponto de enxertia médio do experimento foi atingido aos 154 dias após a repicagem (227 DAS), resultado semelhante ao obtido por GRASSI FILHO et al. (2001) aos 150 dias após a repicagem.

Ao atingir o ponto de enxertia, as mudas do Sistema 1 apresentaram, em geral, as menores médias para todas as características avaliadas. Esta inferioridade deve ser atribuída às diferenças entre os substratos de cultivo, principalmente quanto à composição química e à maior retenção de água do substrato composto pelos resíduos da agroindústria canavieira, pois as mudas provindas dos Sistemas 2 e 3 apresentaram as maiores médias para todas as características avaliadas.

No ponto de enxertia, não houve diferenças entre as médias de altura, número de folhas e área foliar obtidas pelas mudas cultivadas nos Sistemas 2 e 3 . Entretanto, o sistema de blocos prensados (Sistema 3), utilizado para a produção das mudas antes da repicagem, afetou o desenvolvimento das mudas na fase seguinte. As mudas deste sistema, na época da repicagem, apresentaram um sistema radicular bem distribuído lateralmente, não sendo observadas as deformações e redirecionamento de raízes como no caso das mudas cultivadas em tubetes (Sistema 2). Após a repicagem, essas características podem ter proporcionado um melhor desenvolvimento do sistema radicular, favorecendo a obtenção de mudas aptas à enxertia em menor tempo e de melhor qualidade morfofisiológica, com maior diâmetro do caule e maior massa seca do sistema radicular e da parte aérea.

Observou-se que, na menor dose do adubo aplicada (5g planta $\left.{ }^{-1}\right)$, as mudas provindas do sistema de blocos prensados apresentaram médias de diâmetro do caule e massa seca do sistema radicular superiores às dos outros dois sistemas, enquanto as médias de altura, número de folhas, área foliar e peso seco da parte aérea mostraram-se superiores às do Sistema $1 \mathrm{e}$ iguais às do Sistema 2 (Tabela 2).

Os resultados obtidos demonstram que o sistema de produção em tubetes, apesar de todas as vantagens operacionais que proporciona, apresenta efeito restritivo ao crescimento radicular e que o uso de recipientes de paredes ausentes ou perfuráveis poderia trazer vantagens para a propagação dessas mudas. Um sistema radicular mais volumoso tende a conter maior número de ápices radiculares, região em que a raiz é mais eficiente na absorção de água e nutrientes e, principalmente, na produção de reguladores de crescimento (REIS et al., 1989).

Outra vantagem na utilização do sistema de blocos prensados foi a obtenção, no geral, de maior massa seca da parte aérea, que é considerada como uma boa indicação da capacidade de resistência das mudas às condições adversas após o plantio no campo (MORGADO et al., 2000).

Ciência Rural, v.36, n.2, mar-abr, 2006. 
Tabela 2 - Valores médios para altura (H), diâmetro do caule (D), número de folhas (NF), área foliar (AF), massa seca da parte aérea (MSA) e massa seca do sistema radicular (MSR), de mudas de limoeiro 'Cravo' no ponto de enxertia (227 dias após semeadura), que receberam a dose de $5 \mathrm{~g} /$ planta de Osmocote $^{\circledR} 14-14-14$.

\begin{tabular}{|c|c|c|c|c|c|c|}
\hline Sistemas de produção(1) & $\mathrm{H}(\mathrm{cm})$ & $\mathrm{D}(\mathrm{mm})$ & NF & $\mathrm{AF}\left(\mathrm{cm}^{2}\right)$ & MSA (g) & MSR (g) \\
\hline Casca de pinus (tubetes) & $70,7^{\mathrm{b}}$ & $6,9^{c}$ & $38,7^{\mathrm{b}}$ & $741,6^{\mathrm{b}}$ & $14,3^{b}$ & $8,9^{\mathrm{b}}$ \\
\hline $\mathrm{BC}+\mathrm{TF}$ (tubetes) & $134,4^{\mathrm{a}}$ & $8,1^{\mathrm{b}}$ & $55,6^{\mathrm{a}}$ & $1.907,3^{\mathrm{a}}$ & $33,9^{\mathrm{a}}$ & $10,8^{\mathrm{b}}$ \\
\hline $\mathrm{BC}+\mathrm{TF}$ (blocos prensados) & $130,6^{\mathrm{a}}$ & $9,6^{\mathrm{a}}$ & $59,7^{\mathrm{a}}$ & $1.857,7^{\mathrm{a}}$ & $41,2^{\mathrm{a}}$ & $18,2^{\mathrm{a}}$ \\
\hline Média Geral & 111,9 & 8,2 & 51,3 & $1.502,2$ & 29,8 & 12,6 \\
\hline D.M.S. & 20,1 & 1,0 & 8,8 & 543,1 & 10,8 & 4,5 \\
\hline Cv (\%) & 13,2 & 9,3 & 12,6 & 26,5 & 26,5 & 26,0 \\
\hline
\end{tabular}

Médias na coluna, seguidas por letras diferentes, são diferentes em nível de $5 \%$ de probabilidade de erro pelo teste de Tukey. ${ }^{(1)}$ BC: bagaço de cana; TF: torta de filtro.

Em relação à aplicação do adubo de liberação lenta, as mudas do Sistema 1, para todas as características avaliadas, responderam linearmente ao aumento das doses de adubo aplicadas (Figuras 1A a 1F). As mudas provenientes do Sistema 2 não responderam ao aumento das doses aplicadas para nenhuma das características avaliadas (Figuras 1A a 1F) . Com o incremento da adubação no Sistema 3, também não houve resposta das mudas quanto à altura, área foliar e número de folhas (Figuras 1A, 1B e 1F) entretanto, ocorreu um decréscimo nas médias do diâmetro do caule e da massa seca da parte aérea e do sistema radicular (Figura 1C, 1D e 1E).

O substrato utilizado nos Sistemas 2 e 3 apresentou maiores teores de nutrientes, exceção para os teores de $\mathrm{K}$ e $\mathrm{Mg}$, que o substrato utilizado no Sistema 1. Ressalta-se que N e P são nutrientes exigidos em maiores quantidades durante a fase de produção de mudas cítricas. Assim, a quantidade desses nutrientes no substrato composto por bagaço de cana e torta de filtro contribuíram para a ausência de resposta das mudas do Sistema 2 ao incremento da adubação (Figuras 1A a 1F).

O efeito depressivo da adubação sobre o crescimento das mudas provenientes do sistema 3 pode ser explicado pela diferença morfológica do seu sistema radicular que interferiu na sua resposta à adubação, uma vez que, após a repicagem, foi utilizado o mesmo substrato para as mudas dos Sistemas 2 e 3.

As maiores médias observadas no Sistema 1 foram obtidas pelas mudas que receberam a dose de 25 planta $^{-1}$ do adubo, enquanto no Sistema 3 (blocos prensados) as maiores médias foram obtidas com a aplicação de $5 \mathrm{~g}$ planta $^{-1}$ do adubo, proporcionando maior economia no uso do adubo.

Nas doses de 10, 15 e 20 g $_{\text {planta }}{ }^{-1}$, as médias de altura, número de folhas, área foliar, e massa seca da parte aérea das mudas dos Sistemas 2 e 3 foram iguais entre si e superiores às do Sistema 1 . Na dose de $25 \mathrm{~g}$ planta $^{-1}$, verificou-se semelhança entre os diâmetros de caule, número de folhas e massa seca do sistema radicular, das mudas dos três sistemas (Figura 1A-1F).

A produção do limoeiro ‘Cravo' em blocos prensados (Sistema 3) mostrou-se vantajosa pela precocidade em que as mudas atingiram o ponto de repicagem e o ponto de enxertia. Neste sistema, as mudas podem ser obtidas ainda com maior precocidade se novos estudos forem efetuados para encontrar tipos e doses de adubo de liberação lenta mais adequados, determinação da melhor época de repicagem e do volume dos recipientes utilizados após a repicagem, uma vez que o sistema radicular do porta-enxerto apresentou maior desenvolvimento.

A produção do limoeiro 'Cravo' em tubetes preenchidos com substrato composto pela mistura entre bagaço de cana-de-açúcar e torta de filtro (3:2; v:v) até a repicagem e, posterior transplantio para citrovasos com o mesmo substrato (Sistema 2), também foi considerada satisfatória.

\section{CONCLUSÕES}

As mudas do limoeiro 'Cravo' provenientes do sistema de blocos prensados atingem o ponto de

Ciência Rural, v.36, n.2, mar-abr, 2006. 

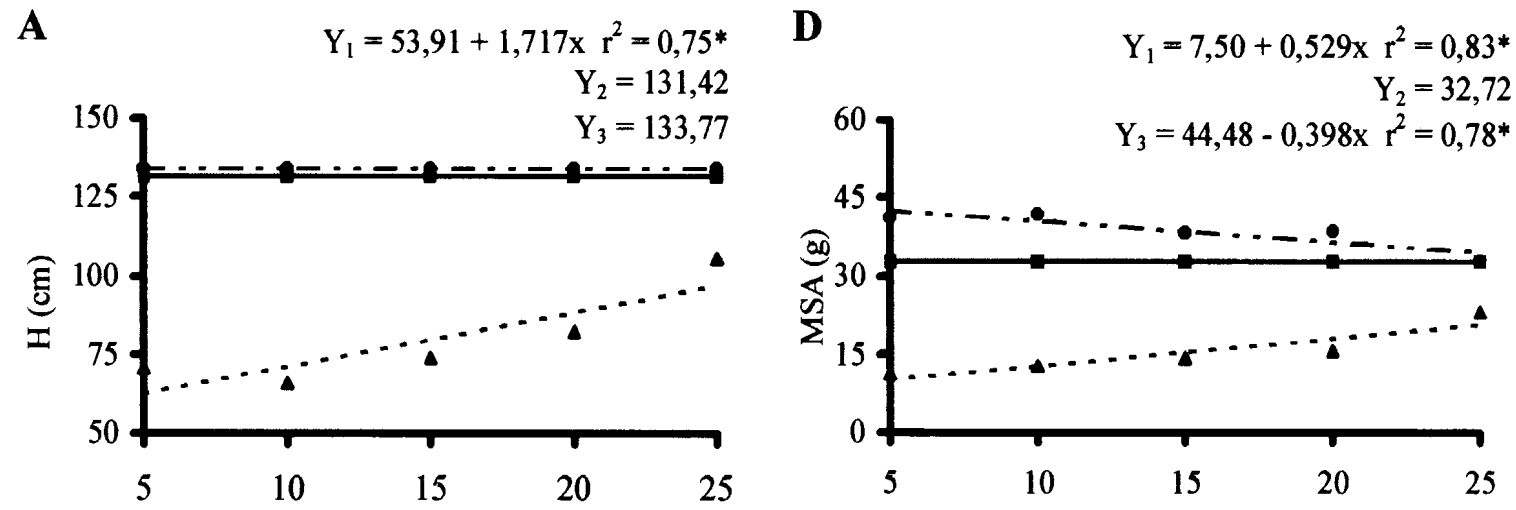

B

$\mathbf{E}$
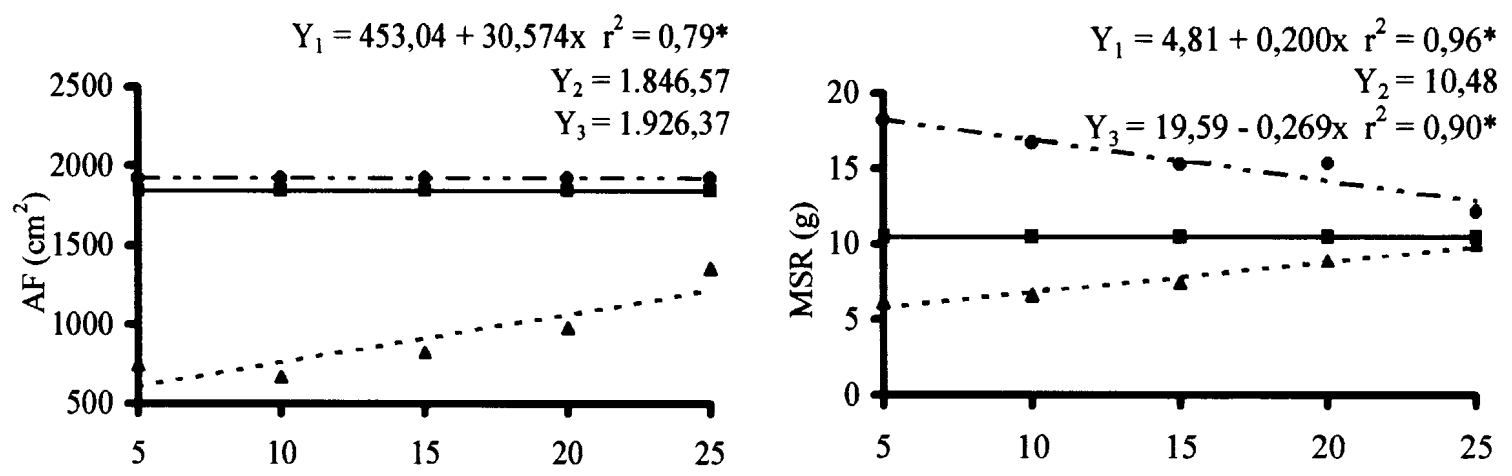

C

$\mathbf{F}$

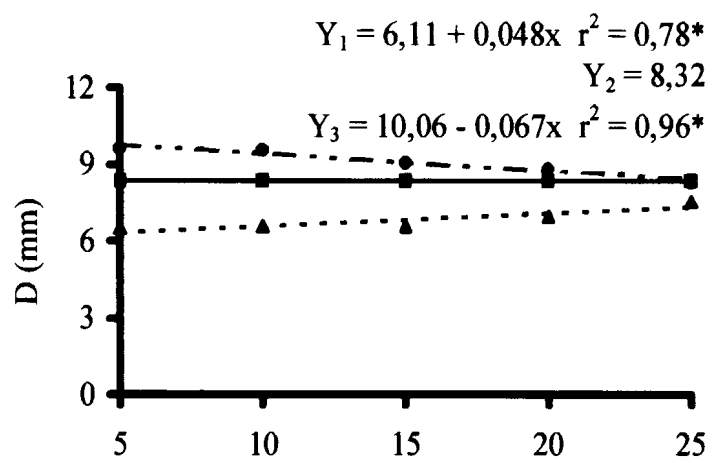

Doses do adubo (g/planta)

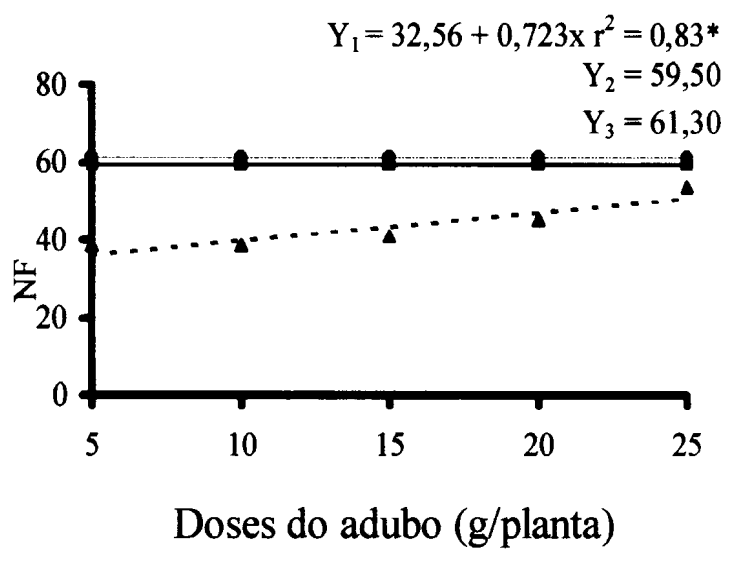

Figura 1 - Efeito das doses de adubo de liberação lenta sobre as características de crescimento do limoeiro 'Cravo' (H = altura; $\mathrm{AF}=$ área foliar; D = diâmetro do caule; MSA = massa seca da parte aérea; MSR = massa seca do sistema radicular e NF = número de folhas) no ponto de enxertia (227 dias após semeadura) em três sistemas de produção de mudas cítrica $\mathbf{\Lambda}$ - Sistema 1, $\mathbf{1}$ - Sistema 2, e - Sistema 3). 
repicagem e de enxertia mais rapidamente que as de tubetes, apresentando maior diâmetro de caule e maior massa seca da parte aérea e do sistema radicular no ponto de enxertia. O substrato composto pela mistura entre bagaço de cana e torta de filtro (3:2; v:v) permite a redução nos níveis de adubação N, P e K em relação ao substrato comercial composto por casca de pínus moída e vermiculita.

\section{AGRADECIMENTOS E APRESENTAÇÃO}

À Fundação Estadual Norte Fluminense (FENORTE) e ao Conselho Nacional de Desenvolvimento Científico e Tecnológico (CNPq) pelo apoio financeiro dado ao trabalho.

Parte da Dissertação de Mestrado apresentada pelo primeiro autor ao Programa de Pós-graduação em Produção Vegetal da Universidade Estadual do Norte Fluminense 'Darcy Ribeiro’ - UENF, Campos dos Goytacazes, RJ, Brasil.

\section{REFERÊNCIAS}

BARROSO, D.G. et al. Qualidade de mudas de Eucalyptus camaldulensis e E. urophylla produzidas em tubetes e em blocos prensados, com diferentes substratos. Floresta e Ambiente, v.7, n.1, p.238-250, 2000.

CARNEIRO, J.G.A. et al. Comparison of production methods for containerized pine (Pinus elliotti) seedlings in Southern Brazil. Metsantutkimuslaitoksen Tiedonantoja, Finland, v.302, p.6-24, 1988.

CARVALHO, S.A. Propagação dos citros. In. Citricultura: inovações tecnológicas. Informe Agropecuário, Belo Horizonte-MG, v.22, p.21-25, 2001.

GRASSI FILHO, H. et al. Efeito de diferentes substratos no crescimento de mudas de limoeiro 'Cravo' até o ponto de enxertia. Revista Laranja, v.22, n.1, p.157-166, 2001.
LELES, P.S.S. et al. Qualidade de mudas de Eucalyptus spp. produzidas em blocos prensados e em tubetes. Revista Árvore, v.24, n.1, p.13-20, 2000.

MARSCHNER, H. Mineral nutrition of higher plants. London: Academic, 1995. 889p.

MORGADO, I.F. et al. Nova metodologia de produção de mudas de Eucalyptus grandis W. Hill ex Maiden utilizando resíduos prensados como substrato. Revista Árvore, v.24, n.1, p.27-33, 2000.

NOVAES, A.B. Avaliação morfofisiológica da qualidade de Pinus taeda L., produzidas em raiz nua e em diferentes tipos de recipientes. 1998. 118f. Tese (Doutorado em Engenharia Florestal) - Universidade Federal do Paraná.

REIS, G.G. et al. Crescimento de Eucalyptus camaldulensis, $\boldsymbol{E}$. grandis e $\boldsymbol{E}$. cloeziana sob diferentes níveis de restrição radicular. Revista Árvore, v.13, n.1, p.1-18, 1989.

REZENDE, L.P. et al. Volume de substrato e superfosfato simples na formação do limoeiro 'Cravo' em vasos. I- Efeitos no crescimento vegetativo. Revista Laranja, v.16, n.2, p.165-177, 1995.

SERRANO, L.A.L. et al. Germinação de sementes de citros, submetidas a tratamento químico e extração manual do tegumento. Informativo ABRATES, v.13, n.3, p.452, 2003.

SHAVIT, U. et al. Release characteristics of a new controlled release fertilizer. Journal of Controlled Release, v.43, p.131-138, 1997.

TOMASZEWSKA, M. et al. Physical and chemical characteristics of polymer coatings in CRF formulation. Desalination, v.146, p.319-323, 2002.

ZEKRI, M.; KOO, R.C.J. Use of controlled-release fertilizers for young citrus trees. Scientia Horticulturae, v.49, p.233241, 1992. 